\title{
Application of the Real Options Method for Innovation Project Investment Evaluation*
}

\author{
Elena Makarova \\ Southern Federal University \\ Rostov-on-Don, Russia \\ E-mail: elmakarova@sfedu.ru
}

\author{
Anna Firsova \\ Saratov State University \\ Saratov, Russia \\ E-mail: firsova@rambler.ru
}

\begin{abstract}
Innovations are regarded as one of the important sectors of the economy and investment in economically developed countries. The underdevelopment of organizationaleconomic forms and the insufficient development of mechanisms for supporting and implementing projects in innovations impede the development in this sphere. The article analyzes the different methods for calculating the value of options. The stages of decision-making support in the implementation of innovation projects that are based on real options method were analyzed. According to the results of the analysis, conclusion was made that when evaluating real innovative investments, Cox-Rubinstein's approach is more acceptable. The binominal model allows obtaining more accurate results and presents a decision tree with variants of branching, which allows visualizing the scenarios and probabilities of these solutions.
\end{abstract}

Keywords-innovation project; project investment; real options method; binomial model; project efficiency evaluation

\section{INTRODUCTION}

Nowadays, in economically developed countries, innovations are regarded as one of the important sectors of the economy and investment. Innovations are the source of economic development and the expansion of new technological structures and the international competitiveness of countries. According to UNCTAD, the growth rate of international trade in innovation creative services in 2016 was $3 \%$ and it was on the second place after the $4.5 \%$ growth of the IT and computer sector. All this testifies to the growing importance of innovations and contribution to economic development in modern conditions and the prospects for the development of organizational and financial mechanisms for investing in these areas [1], [2].

At present, the underdevelopment of organizationaleconomic forms and the insufficient development of mechanisms for supporting and implementing projects in innovations impede the development in this sphere, and the structure of funding sources reveals a disproportion between the needs of the economy and the possibilities of financing these projects. One of the main determinants that have a negative effect on financing is the insufficient development

*Fund: The reported study was supported by Russian Foundation for Basic Research, project "Development of economic and mathematical tools for managing and evaluating the effectiveness of innovative projects based on binomial models" (Project No.: 18-010-00793). of expert procedures and methods for analyzing investments in these areas.

A possible method of decision support in the implementation of innovative is the method of real options. Using the concept of the real options method in the implementation of innovative projects is based on the assumption that the company needs to form and substantiate an innovative proposal, carry out the necessary research with the design and testing of prototypes, and also need to build or acquire assets such as buildings, structures, equipment and other production investments for a period of time.

Evaluation of investment projects using the real options method implies that any investment opportunity for a company can be considered as a financial option, that is, the company has the right, and not the obligation to create or acquire these assets for a certain period of time. This makes it possible to clarify the evaluation of the effectiveness of an investment project, taking into account decisions that can be made in the course of its implementation on the basis of the consequences of the uncertainty of the future. At the same time, an analysis from the standpoint of real options allows one to find out the profitability of many projects with net present value (NPV), estimated by traditional methods, close to zero or negative.

Investment of innovation project implementation is a complex management task and it is extremely important to correctly evaluate the results of investment activities. A welldesigned investment project ultimately answers the question is it worth investing in this business at all and will it brings in revenues that will pay all the costs of labor and resources? The considered toolkit of the real options method makes it possible to change and make optimal decisions in the future during the implementation of projects in accordance with the incoming information. At the same time, the ability to make and change decisions in the future is quantitatively evaluated at the moment of analysis.

\section{THEORETICAL ANALYSIS}

The implementation of innovation project investment in Russia is carried out under conditions of increased uncertainty caused by the essentially non-stationary nature of the Russian economy, as well as global processes. 
General theoretical approaches of innovation projects evaluation are based on traditional methods of effectiveness analysis, calculating the impact of risk and uncertainty on project results, and fully disclosed in the domestic and foreign scientific works of V.M. Anshina, V.L. Barancheeva, A.A. Dagaeva, N.I. Ivanova, L.K. Gapenski, A. Hamilton, G. Sabato, B. Santo, U. Sharp, S.V. Valdaytseva and others. Innovation projects evaluation, concerning problems of the effective organizational structure construction for project management are researched in the works of T.M. Bronnikova, I.I. Mazur, S.A. Titova, V.D. Shapiro V.V. Voropaeva, and etc.

Real options method (ROV, Real Options Valuation; ROA, Real Options Analysis) is a method of evaluating innovation project investment, taking into account the possibilities of changing conditions and choice possibilities.

The real options method first appearing in the works of S. Myers (1977) has been studied for about thirty years [3]. Real options concept have been described and carefully studied by P. Boehr, R. M. Grant, A. Damodoran, J. Rosenberger, J. Rosh, L. Trigeorgis and etc. [4], [5], [6], [7]. For the evaluation of the real options value it was meant to use the value of financial options in the F. Black, R. Merton and M. Scholes formulas (1973) [8]. The application of the mathematical apparatus for calculating the option costs evaluation using the Black-Scholes Option Pricing Model and R. Braeley, S. Myers binomial model was considered it in detail.

The Real Options Analysis (ROA) method emerged in the practice of analyzing the effectiveness of investment projects as a phenomenon used by managers intuitively, this method also has an accumulated conceptual apparatus for developing and making design decisions, it is a method specifying the project net present value (NPV) and allows in some cases to more adequately assess the value of real assets and more flexibly manage them.

In domestic researches, the theoretical issues of innovation projects evaluation are well developed in the classification of real options and the need for their application to the project analysis. In early 2000s the real options method has been developed in Russian Federation, in the researches of $\mathrm{N}$. Bruslanov, M.A. Kanev, D.Y. Khomutsky, A.A. Krukovsky, M. V. Lychagin, A. K. Pirogov, A. V. Vorontsovsky, M. A. Limitovsky, A. V. Bukhvalov, E.A. Chernykh etc. [9], [10], [11]. The real options method is first and foremost an additional tool in any negotiation process, starting from the justification of investment attractiveness and ending with the discussion of the sale of the company. It quantifies intangible strategic opportunities, the value of which is intuitively recognized by everyone.

However, the issues of structuring real options throughout the life cycle of the innovation projects evaluation, the use of binomial models in assessing the effectiveness and risks of implementing innovative projects and the methodology for modeling the evaluation characteristics of innovative projects at the current stage have not been adequately studied.
That is why the use of a real option provides an opportunity during the implementation of an innovative project to flexibly change management decisions; this is a phased implementation of the project in the face of uncertainty with the discrete formation of new project conditions until the investment is fully implemented.

\section{Methodology OF InNOVATION Project FinANCING}

The use of the real options method is the possibility of a phased assessment of innovation project financing in the face of uncertainty, possibility of adaptation to changing external conditions and reducing the risk of the impact of uncertainty on future project results. When real options are included in the project, the project will be able to adapt to changing external conditions, thereby reducing the risks of the impact of uncertainty on future project results.

Recommendations of choosing a binomial model for innovations projects financing depend on the type of real options.

"Sizing" options mean the possibility of leaving the project in the future or, on the contrary, its expansion depending on the financial results of the project, including options for development and growth (growth options), CALL option with favourable developments; options to reduce, PUT option at unprofitable project; options for termination of the project (options for abandon) and exit from business, option-he PUT at a project unprofitability.

"Flexibility" options mean the ability to change and adjust project parameters, including options to switch and temporarily stop the project; options to replicate experience and successful business model (options to replicate).

"Timing" options mean the ability to postpone investment decisions when there is insufficient information and waiting for the necessary information to appear in the future, including options to postpone the start of a specific project phase (options to defer); sequential investment options (timeto-build options); fundamental options; composite multifunctional options (compound options).

According to M.A. Limitovsky, while using the method of real options in assessing the effectiveness of the implementation for innovation projects, it is necessary to consider the following key parameters that affect the results and cost of an innovation project: uncertainty of future revenue streams; costs of ownership and implementation of real options for the project; the present value of the future income stream (NPV); expected commercial value of the project (ECV); the cost of additional investments arising from the additional development of project implementation scenarios; discount rate with risk premium; time period until the option is exercised; conditions of the option.

In modern domestic and foreign practice of innovation project evaluation, the following methods for calculating the value of real options are distinguished:

- based on the Black-Scholes Option Pricing Model (1973), (BSOPM) for the valuation of options, which 
is the most popular real value valuation model in the scientific and practical environment;

- based on the Cox-Ross-Rubinstein model of the binomial tree (1979), (Binomial options pricing model, BOPM);

- a model of the method of assessing real options Merton (1974);

- the method of valuation of real options Datar-Metews (2004), which was specifically designed for assessments in the field of corporate investment; options (2009);

- simulation method.

The possibilities of using the real options method of innovation project evaluation arise when:

- negative or close to zero value of the NPV indicator of the project evaluation;

- there is a high degree of uncertainty in the results of the project evaluation;

- the dependence of the financial result of the project on the decisions made by the management;

- the project management has the desire and ability to make flexible decisions on a large number of project control points when additional information arises or the project implementation conditions change;

- the presence of the special importance of innovation project evaluation for a more accurate determination
- method of fuzzy payments for the evaluation of real

of the fundamental factors and risks of the project and for hedging its failure and ineffectiveness of implementation and justification of alternative development options for the project.

When using the method of real options in assessing the implementation of innovation projects a hierarchical decision tree and simulating possible scenarios for implementing an innovation project, it is necessary to consider the main parameters that affect the results and cost of an innovation project, including the costs of owning and implementing real options on a project, the uncertainty of flows future revenues, the expected commercial value of the project, the present value of the stream of future revenues, the cost of additional investment in the multi-stage and multi-priced implementation of an innovative project, the interim period of an innovative project, the conditions for the execution of an innovative project, the discount rate, taking into account the risk premium [12].

The technique of building a binomial model is more complicated, but it provides increased accuracy of results when there are multiple sources of uncertainty or decision data. It is based on two assumptions: in one time interval there can be only two scenarios (the worst and the best); investors are neutral to risk. The calculation of the value of an option by this method, in essence, is a movement along the "decision tree", and at each of its points the best of them is found. As a result, cash flows arising as a result of future decisions converge to the present value of the project (in "Fig. 1", t refers to the period, s refers to the initial value of the underlying asset, $\mathrm{u}$ refers to the increase in value and $\mathrm{d}$ refers to the decrease in value) [13].

$$
\mathrm{t}=3
$$

\section{Successful project} completion

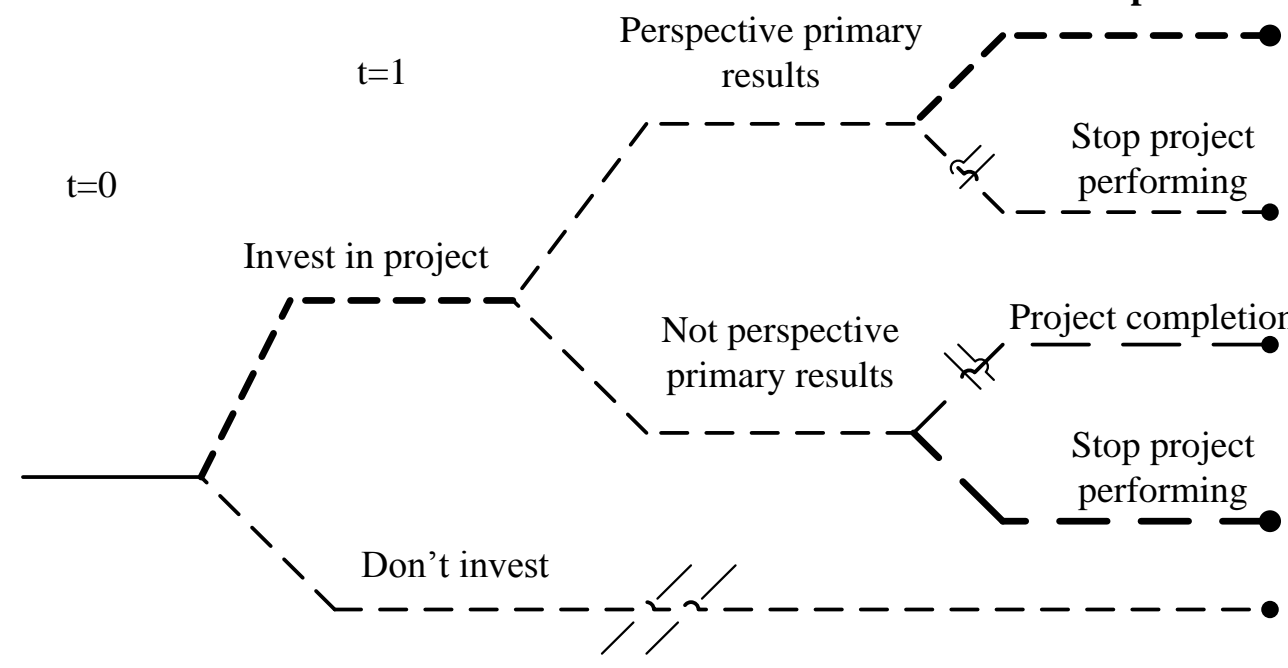

\section{Positive net income}

Loss of initial expenses
Negative net income

Loss of initial expenses

No costs or expenses

Fig. 1. An example of the innovation project development with a choice: the initial decision to conduct research and development activities makes it possible to invest in the completion of development. 
In most innovation projects there are basic options, as shown in "Fig. 1" as an example of a simple two-stage decision tree: the first decision is made when launching a project; a later choice was made at the completion of the development of project.
Between these selections, innovation project managers can observe the elimination of uncertainties, such as the success of initial research. They can then proceed to the second stage if the initial results are promising or otherwise suspend the project.

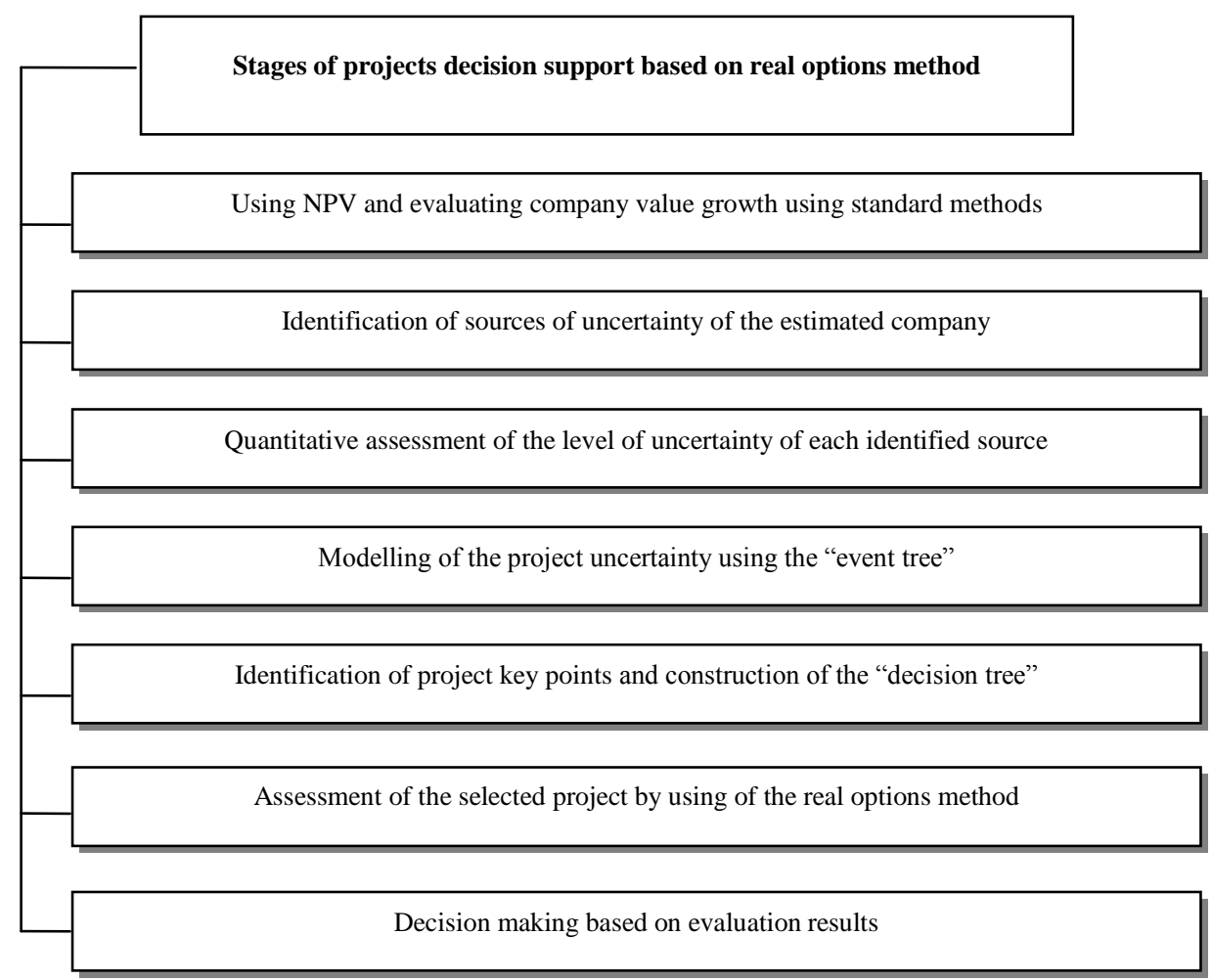

Fig. 2. Decision support stages algorithm of the innovation project implementation, based on real options method.

The stages of projects decision support based on real options method are shown in "Fig. 2". The main limitations that require caution in using the real options method for the innovation project evaluation are as follows:

- the need to ensure the receipt of reliable baseline data for calculations;

- the need to eliminate double counting of options;

- not all available opportunities are real options;

- the danger of overstating the cost of an unprofitable innovation project;

- adoption of a temporary commercial advantage for a possible option for timing due to market leadership and the strategy of "skimming";

- frequent revision of plans and defocusing of the company's strategy objectives due to the implementation of managerial flexibility provided by options;

- lack of support in the corporate culture of the company, inability or unwillingness of the management and employees of the company to be flexible and mobile;
- lack of qualified specialists to support decision making on innovation projects based on the real options method.

\section{CONCLUSION}

Summarizing our research we believe that the BlackScholes BSOPM model, based on the premise of continuous time tracking, is more appropriate when evaluating financial options - you can buy or sell them at any time because there is a liquid standardized market. But real investment is not an exchange, and it's hard to sell your right to participate in a project.

When evaluating real innovative investments, CoxRubinstein's approach is more acceptable, since real investments are not so liquid that you can sell your right to participate in a project at any time. The binomial model allows obtaining more accurate results and presents a decision tree with variants of ramifications, which allows visualizing the scenarios and probabilities of these solutions.

This option pricing model has several advantages compared to other real options models and can illustrate the process of making intermediate decisions in the period before the expiration date of the option, which allows you to intuitively understand how to act at each point in time. 
The binomial model, like the Black-Scholes model, is based on the use of a risk-neutral argument. Because of this, it does not require the use of risk-adjusted discount rates, the need for which sometimes causes problems when real options are valued by other means. When using a binomial model in the sphere of innovations, it is necessary to build an investment project value tree and, on its basis, an option value tree, which are then folded. When constructing an asset value tree, you can consider project risks in scenario values, and not in the discount rate.

\section{REFERENCES}

[1] N. Malshina, A. Firsova. Mechanisms of innovative projects financing in the culture industry on the basis of public-private partnership. Proceedings of the 3rd International Conference on Judicial, Administrative and Humanitarian Problems of State Structures and Economic Subjects. Series: Advances in Social Science, Education and Humanities Research. 2018, vol. 252, pp. 100-105.

[2] E. Makarova, A. Firsova. Computer Cognitive Modeling of the Innovative System for the Exploration of the Regional Development Strategy. Computer Modelling in Decision Making. Proceedings of the Second Workshop on Computer Modelling in Decision Making co-located with the VI International Youth Research and Practice Conference on Mathematical and Computer Modelling in Economics, Insurance and Risk Management (MCMEIRM 2017). Saratov, 2017, pp. $113-125$.

[3] St. Myers. Determinants of corporate borrowing. Journal of Financial Economics, 1977, no. 5, pp. 147-175.

[4] R. M. Grant. Modern strategic analysis. SPb.: Piter, 2011, 560 p.

[5] J. Rosh. The value of the company: From the desired to the real. Minsk: Grevtsov Pablisher, 2008, 352 p.

[6] L. Trigeorgis. Real Options and Interactions with Financial Flexibility. Financial Management, 1993, vol. 22 (3), pp. 202-224.

[7] A. Damodoran. Investment valuation. Tools and techniques for assessing any assets. Moscow: Alpina Business Books, 2004, 1342 p.

[8] F. Black, M. Scholes. The Pricing of Options and Corporate Liabilities. Journal of Political Economy. 1973, no. 81, pp. 637-659.

[9] M. A. Limitovsky. Investment projects and real options in emerging markets. Moscow: Yurayt, 2008, 464 p.

[10] A. V. Bukhvalov Real real options. Russian Journal of Management, 2006, no. 3, pp. 77-84.

[11] E.A. Chernykh Innovations as real options, or planning unpredictable]. Quality management, 2008, no. 3, pp. 192-201.

[12] A. A. Firsova. Main characteristics of real options in the implementation of innovation projects. Izv. Saratov Univ. (N.S.), Ser. Economics. Management. Law. 2018, vol. 18 (2), pp.162-168. DOI: 10.18500/1994-2540- 2018-18-2-162-168.

[13] E. L. Makarova. Development of economic and mathematical tools for managing and evaluating the effectiveness of innovative projects based on binomial models. Herald of Adygea State University. Series Economy, 2018, no. 3, iss. 225, pp. 271-278. 